\title{
MANAGING CULTURAL HERITAGE WITH INTEGRATED SERVICES PLATFORM
}

\author{
F. I. Apollonio ${ }^{1}$, M. Gaiani ${ }^{1}$, S. Bertacchi ${ }^{1, *}$ \\ ${ }^{1}$ Dept. of Architecture - Alma Mater Studiorum University of Bologna, Italy (fabrizio.apollonio, marco.gaiani, \\ silvia.bertacchi)@unibo.it
}

KEY WORDS: Cultural Heritage, 3D models, $\mathrm{CH}$ data life cycle management, Information System, Integrated service

\begin{abstract}
:
Cultural Heritage management is a topical issue facing administrators, professionals and scholars involved in documentation, restoration and enhancement of the cultural assets. In the paper, after a general framework on the state of the art in the sector, two recent experiences are reported about Information System and integrated service platform for managing Cultural Heritage that authors contributed to develop with the aim of providing experts of the field with effective and flexible tools: the Information System for the restoration of the Neptune's Fountain and the SACHER 3D Life Cycle Management for Cultural Heritage service. The paper describes in detail the two case studies and some possible implementation designed but not yet achieved for the latter, and finally presents some starting points for future research.
\end{abstract}

\section{INTRODUCTION}

Cultural Heritage $(\mathrm{CH})$ management is currently a hot issue, especially in a country like Italy, holding the lead in the world for the largest number of historical, traditional and cultural assets, including monuments, museums, archaeological parks (MiBACT, 2019) and even UNESCO cultural sites (ItalyUNESCO WHL, 2019). Over past years, digital innovation has greatly simplified the management of the conservationrestoration of Cultural Heritage; however, managing the cultural assets often means dealing with thorny problems, ranging from administrative or bureaucracy-related obligations to public funding, definitely to the actual management of the Cultural Heritage with aware and targeted measures for its preservation and maintenance. The greatest difficulties are related mainly to various disciplines and professionals involved and, among others, the heterogeneity and fragmentation of data, the dispersion of information in isolated databases, the lack of usability of complex systems, to name a few.

Moreover, this complex process cannot be limited to a restricted period, but it is of prime importance that the whole life cycle of the $\mathrm{CH}$ is considered, from knowledge and management to restoration and enhancement, in addition to foresee the interoperability of every activity with other systems over time and the gathered data stability and long-term preservation too.

These days the use of powerful technological systems, i.e. software applications, integrated service platforms and 3Dbased Information Systems (IS), is a widespread solution commonly adopted for supporting the management of $\mathrm{CH}$ during the entire process of linking data to a cognitive spatial Information System, even using the 3D digital model as visualisation and connection tool, and also for disseminating towards the general public.

In recent years, digital innovation is increasingly influencing the Cultural Heritage domain, and documentation and information representation of Heritage sites are rapidly evolving, i.e. introducing of 3D models, which restoration operators strongly require. Advantages include rapid, multiple data collection, easy dissemination of contents among users, easy portability, remote cooperation, online accessible sources, powerful tools for quantitative query; innovation in accurate and effective representation too counts many progresses in the domain.

Though, some problems still awaiting resolution exist, directly related to the lack of automation of the whole workflow of data gathering, curation and dissemination, thus far not solved, for which few suggestions will be discussed after presenting the latest advancements.

In detail, the paper describes the solutions in which our group was involved or that have been directly developed in the last years, primarily focussing on the main problem introduced by the 3D nature of the object managed and of the 3D based IS: the Information Conceptual Model (ICM). In our case the development of the ICM is not only related to the kind of data and their semantic links, but also it is strongly rooted in the processes of digital data generation, allowing easy organisation and retrieval of different types of data and their environmental links.

The paper is organised in sections addressing the following topics: Section 2 sketches relevant related works and previous solutions for specific fields; Section 3 summarises experiments carried out by the team to date, presenting two recently developed case studies; Sections 3.1 and 3.2 describe in detail the two developed works, the ICM (Section 4) and their comparison within the existing state of the art (Section 4.1); Section 5 presents possible implementation of the IS; while Section 6 concludes the paper with final remarks.

\section{RELATED WORKS}

Among the various activities for the preservation of a Cultural Heritage object, documentation, cataloguing and historical analysis is one of the most critical aspects of the current and future Heritage monitoring and must be of primary concern to ensure information over time for future reference.

The problem has been addressed for years, in order to find an integrated and effective system for the management of the huge

* Corresponding author 
amount of varied information related to Cultural assets (technical and scientific data, texts, drawings and images, finally 3D digital models), also taking advantage of new technological advances in specific domains.

This section is aimed to briefly provide some key-reference to past experiences carried out in the domain of integrated service platform devoted to the management of Cultural Heritage, including some milestones in the up-to-date international scientific research, as more extensively discussed in overview on the state of the art of different existing platforms for visualising and managing $\mathrm{CH}$ (Foni et al., 2010; Pintus et al., 2016; Scopigno and Dellepiane, 2017).

Some previous solutions for specific fields were promoted within the framework of remarkable restoration projects by the Italian Ministry of Culture, such as the SICaR Information System (Baracchini et al., 2003; Siotto et al., 2016), the official web-platform for georeferenced documentation providing professionals with more user-friendly tools in public restoration sites (SICAR, 2019).

The first synergistic effort also for large and complex sites considered the creation of stand-alone Information Systems, at a later time web-based platform, allowing a multidisciplinary and collaborative work by giving access to a wider corpus of information previously inconceivable.

That is the case of various solutions developed starting from the last decade leading as subsequent progression towards more advanced developments, only to mention some of the less recently developed by authors (Gaiani, 2012), e.g. Ancient Appian Way 3D Web Virtual GIS (Gaiani et al., 2001), PalladioLibrary and Andrea Palladio-3D geodatabase (AP3D) (Apollonio et al., 2013; Baldissini and Gaiani, 2014; Apollonio et al., 2015; Gaiani et al., 2015a; Beltramini and Gaiani, 2018), and Pompei 3D GIS Unified IS (Benedetti et al., 2010).

Saving in time, better dissemination and sharing information were the first approach towards a more inclusive work and a change of operator's mindset, usually withdrawn into its own specific discipline. The fairly recent inclusion of 3D-based contents like intuitive interface, especially reality-based ones, as centre of IS visualisation, archiving and data recovery, was another step towards efficiency for connection of information of various kinds to the $3 \mathrm{D}$ artefact.

Compared to some ten years ago, most problems related to portability and sharing contents have been overcome by technological progress itself, being connection faster and stable and even though files are larger in size, storage is less of an issue than before; however, some problems still need to be tackled more efficiently.

At present the research in the field is wide-ranging and there exists a varied range of new generation web-platforms for $\mathrm{CH}$ data management available for end users, even open source, as advanced professional tools designed for operators working in the domain of cultural assets for supporting Cultural Heritage experts in their investigations. Recently developed applications are more or less flexible outside their scope, not all suitable for non-experts users, each one addressing particular needs and giving priority to various aspects: (i) ease of use by non-expert end users both for quick and simple annotation on $3 \mathrm{D}$ representations and disseminating analysis and research outcomes (Shi et al., 2016; Wang et al., 2018); (ii) effective visualising methods and viewer platforms for 3D artefacts, complex 3D meshes and point clouds (Galeazzi et al., 2016); (iii) semantic-aware $3 \mathrm{D}$ representation for recording and integrating multidisciplinary observations of the conservation state into structural spatialised data (Carboni and De Luca, 2017; Messaoudi et al., 2018), tools for Heritage Building Information Modeling (H-BIM) solutions by enabling semantic
3D data (Apollonio et al., 2017c) and relying on a computational ontology for Cultural Heritage domain modelling and ontology-based web platforms for managing extremely large amounts of information (Garozzo et al., 2017), semantic reality-based 3D digital models of architecture acquired by means of photogrammetric or TLS customised workflows used as documentation containers (Gaiani, 2015) and for hypothetical reconstructions of completely or partly missed architecture (Adembri et al., 2017), 3D environment to annotate textual, numerical or graphical information directly onto the high resolution 3D model (Soler et al., 2017; Apollonio et al., 2018b), Information Systems and advanced diagnostics tools to support restorers in their investigation (Apollonio et al., 2017b; Apollonio et al., 2018a).

Another issue was a suitable retrieval system for stored information with relevance for the user and in the form more consistent with his own interests. Earlier indexing methods used from visual to textual up to three-dimensional basis for relational databases, now looking towards cloud computing technologies with unstructured data advanced search (Figure 1).

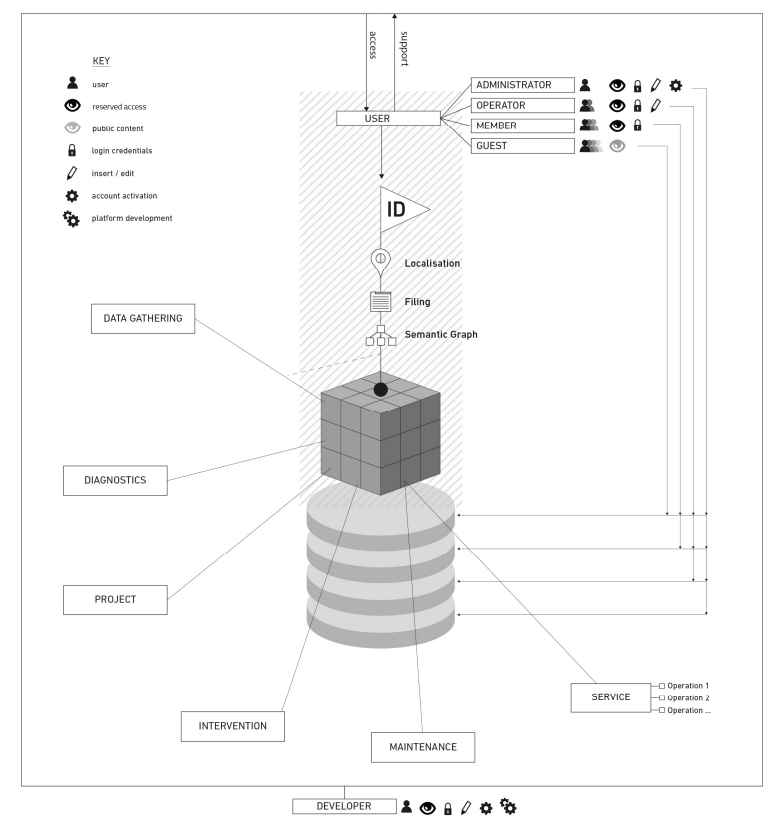

Figure 1. Design of the integrated data management Information System for SACHER 3D CH

\section{CASE STUDIES}

At present, despite a great deal of effort made to promote digitisation of sources, in many domains the process is still ongoing and standardisation for documentation procedures is still lacking; for this reason, there exist numerous archives preserving fragmented and heterogeneous sources, not-easily portable or interoperable between systems. In particular, it follows that data retrieval on monuments and historic buildings is time-consuming and causes waste of resources, preventing an easy and quick share of contents among professionals.

On the contrary, a proper storage and recording of information improve and simplify the monitoring for documentary and operational purposes prior to the restoration project, during the restoration site interventions and related to the subsequent maintenance activities.

In this light, some latest successful experiences are reported, carried out within a short space of time, namely two 
Information Systems both developed - albeit with different tools and facilities - with the objective to provide operators of the sector with an effective tool for the management of the $\mathrm{CH}$ life cycle: (i) the Neptune's Fountain Information System (see Section 3.1) and (ii) the SACHER 3D Life Cycle Management for Cultural Heritage service (see Section 3.2).

Both applications were designed for professional users with a partial opening towards the public (citizens and tourists). They are able to support different activities and to run on the most commonly used devices, and present a scalable and userfriendly interface; the latter especially focuses on acquiring and sharing results on a Google-based map for geo-locating $\mathrm{CH}$. The applications works at different scale: the first one is focused on knowledge management, restoration and maintenance of a specific monument or artefact, the second one aims to the management of monuments or architectures complexes at the urban or whole site scale, allowing a well-coordinated multiscale management scenario.

The team has collaborated actively to the development of both IS. To be precise:

(i) in the Neptune's IS, the first task carried out was the study of the most efficient semantic partition of the 3D model in hierarchical levels, finally achieved splitting the digital model into different levels according to elevation, and subsequently into sub-elements consistent with the morphological features and constituent material of each part (Figure 2). The definition of the semantic structure was instrumental in reaching a clear hierarchy of the monument and so making it more effective for information to be linked to the $3 \mathrm{D}$ elements without being scattered on an overly extended surface, conversely in the correct level of detail. Moreover, another essential task was the development of the conceptual data model of the Information System in order to explore possible relationships between data, involved operators, operating fields, processes and activities, and chronological steps of the restoration project of the fountain, for a rapid online dataentry and query in the web platform (Apollonio et al., 2017a);

(ii) in the SACHER project the team was in charge of two main tasks: (a) the photogrammetry-based acquisition of the case study (Palazzo del Podestà, Bologna); (b) the data modelling of the SACHER 3D $\mathrm{CH}$ service in terms of designing processes and tools for restorers or administration operators. The first activity was carried out in stages, capturing the whole block for photogrammetric reconstruction based on a customised workflow (Gaiani et al., 2016c) and planning a subsequent specific campaign to assure colour fidelity to the 3D model (Gaiani et al., 2016a; Gaiani et al., 2017); thus the digital 3D model has been semantically structured (Figure 3) following the architectural categorisation into elementary elements according to architectural features (Ballabeni et al., 2015; Apollonio, 2018). For the latter, with the help of skilled restorers and the collaboration of a multidisciplinary working team, a complete and customised service has been modelled on the real needs of on-site workers, providing suitable solutions to the critical issues (e.g. simple integration of fragmented data by various archives, interoperability with existing platforms, storage of large files, reliable visualisation of 3D reality-based models, quick connection of information to the semantically split digital surface, user-friendly tools for specific data-entry and documentation query activities, usable end-user interface for non-experts, flexibility of the service to adapt to various architectural categories).

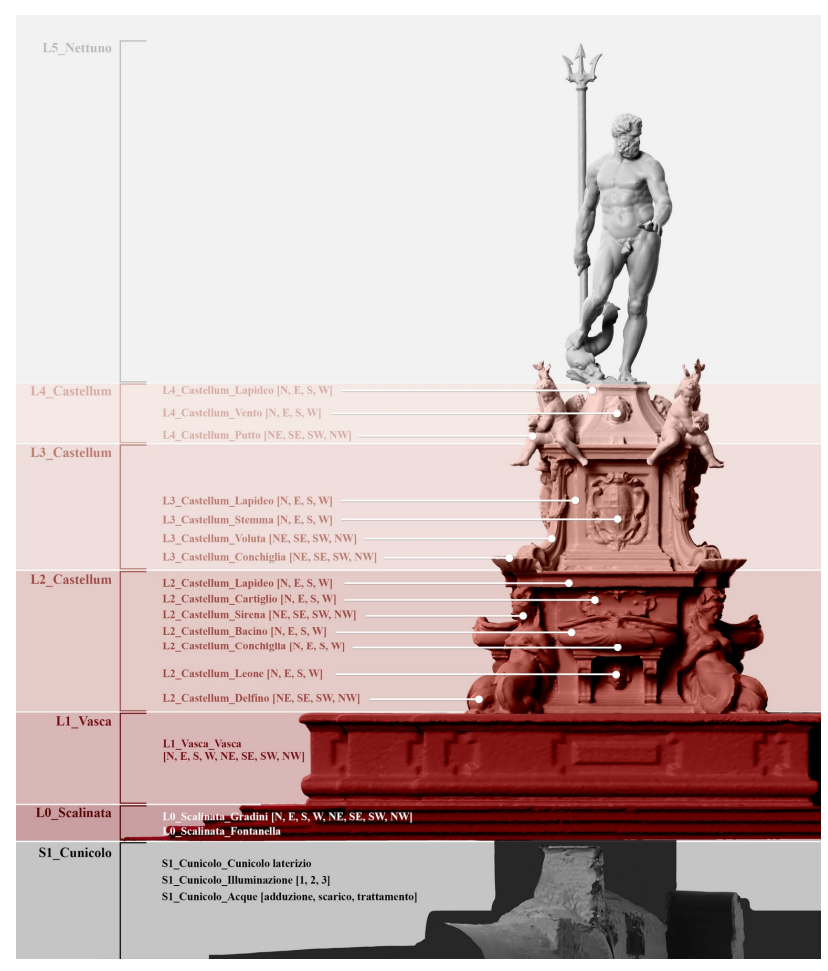

Figure 2. Semantic partition of the 3D digital model of the Neptune's Fountain and its levels and sub-elements

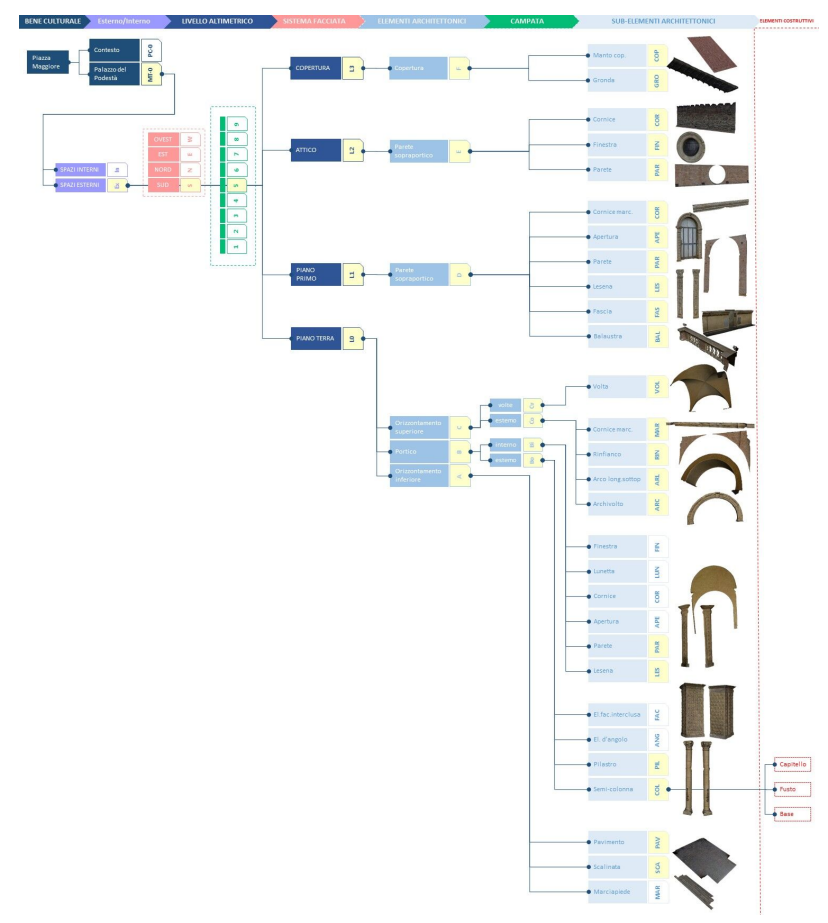

Figure 3. Semantic tree of the 3D model of the Palazzo del Podestà's portico, Bologna, divided into levels, architectural elements and sub-elements

\subsection{Neptune's Fountain IS}

The Neptune's Information System (IS) was created on the occasion of the restoration of the Neptune's Fountain in Bologna (2016-2017) to digitally support the multidisciplinary 
restoration activities on the monument for documentation purposes.

The University of Bologna, jointly with ISCR and ISTI-CNR and thanks to the cooperation of the Municipality of Bologna, designed a comprehensive 3D-centred web-based IS, used onsite to collect all the documentation and data acquired and produced during the restoration process by a heterogeneous team of professionals counting more than 40 experts (not only restorers but also hydraulic and structural engineers, architects, art historians, physics-biology-chemistry researchers, geomatics experts, computer and information scientists). The IS provided innovative, efficient and user-friendly management to the entire process of collection, preservation and retrieval of data and related information from the early diagnostic and planning phase to the actual intervention step (Apollonio et al., 2018b).

The Neptune IS structure is based on an accurate 3D digital model of the monument built and organised as a semantic cognitive system with a defined granularity, supporting data connection with operations. The core of the system is precisely the 3D model, giving access to all textual, photographic and vector information related to a structured list of possible activities and processes.

The IS includes suitable solutions for (a) data query, (b) dataentry, (c) visualisation/navigation and (d) management of $\mathrm{CH}$ contents especially for professionals involved in the topic: in particular, (i) advanced structured search filtering system by user selection of 3D elements with compass to be oriented among similar parts, or full-text search features on main topics and relational fields listed as operations; (ii) easy portability and sharing of graphic, textual, visual, three-dimensional and vector materials via structured uploading system with dropdown menu and pre-filled title according to the user choice; (iii) a 3D online presenter based on 3D-HOP (Potenziani et al., 2015) suitable for an easy navigation in the virtual space, complete with interactive tools for a deeper knowledge and understanding of the complexity of the object, that is the interconnection among operations and information data; (iv) management tools for accounts and users are intended only for admins.

The application is mainly designed to promote research and study advancements among scholars and restorers and allow the management by the local administration; additionally a released public version without sensitive documents can be accessed online from a wider audience (Fontana del Nettuno, 2019).

At the end of the restoration the Neptune IS counts the presence of nearly 10,000 photos taken before and during restoration to document each step of the cleaning activities, in addition to 11 scientific reports, videos of the preliminary inspections and restoration processes, original 3D survey data of the whole fountain; these numbers are steadily increasing because the IS is still operational.

\subsection{SACHER 3D CH service}

The 3D Life Cycle Management for Cultural Heritage Information System is part of the SACHER project, financed by Regione Emilia-Romagna within the European Regional Development Fund (POR FESR 2014-2020) and led by CIRI ICT-University of Bologna (2016-2018).

Assuming that the Cultural Heritage management system was lacking in efficient ICT platforms for the management and integration of heterogeneous and fragmented data sources and interconnection between private and public subjects involved in $\mathrm{CH}$, the SACHER project (Smart Architecture for Cultural Heritage in Emilia-Romagna) provided a distributed, open source and federated cloud-computing-based platform able to support the complete life cycle management of various kinds of data concerning cultural assets (Bertacchi et al., 2018). The general purpose infrastructure in fact integrates a variety of user-friendly services for supporting professionals in the field of $\mathrm{CH}$, with advanced facilities and customised interface design for cultural services (Apollonio et al., 2017d).

In particular the 3D Life Cycle Management for Cultural Heritage service (SACHER 3D CH, 2019), was designed to support both cultural assets management and restoration interventions and is specifically targeted at (i) the team of professionals involved in the numerous phases and working activities of the restoration process (such as restorers, archaeologists, architects, engineers, operators, technicians, etc.) and (ii) the public entities supervising Cultural Heritage. The advanced system is based on 3D digital models of the architectural object, semantically split into main architectural elements to support a proper storage of the numerous data generated during the restoration process. The service was intended as a simplified administration system facilitating the management of large number of cultural items spread on the national territory with customised access for different users and groups of users thanks to a diversified access and team collaboration solution; it is accessible online in multi-user mode on different devices, and suitable for supporting on-site work. The released version includes some key features, namely (i) Cultural Heritage location on map to check listed buildings and monuments at a glance in a defined area, (ii) identification records for each building with pre-filled dropdown listing officially accepted terms for correctly describing architectural features, (iii) intuitive and customised graph definition according to user's chosen granularity and tailored semantic tree for needed complexity; (iv) virtual workspace for navigating/connecting information to reality-based 3D models provided with customised interactive tools (Figure 4); (v) userfriendly data-entry system for easily gathering data and associating labels to contents and 3D links to digital models, (vi) assisted and advanced query for targeted information retrieval.

\section{THE ICM}

Both systems (Neptune's IS and SACHER's 3D Life Cycle Management for Cultural Heritage Information System) have been conceptualised to model the workflow of the life cycle and/or restoration management, driving all the operators and covering all the phases and kind of data involved (Apollonio et al., 2012). The whole structure of the workflow model focuses on the concepts of operator and record: the operator is the data provider (when data are implemented) or consumer (when data are queried); the record is the single action aimed to store data or information. The concept of record accounts all the works and activities connected to the Life Cycle of cultural assets (carried out by restorer, manager, photographer, art historian etc.). A record requires to digit all the data needed for basic indexing, i.e. dates, work phases, people involved, making it a general, multi-purpose container, suitable for all the possible annotations/works. A record is a horizontal data paradigm, while vertical relationships are obtained by grouping temporal succession and interrelated connection of different records. Each record is defined by its own properties: (a) identification of the operator and (b) date/time of data entry; (c) the field of interest; (d) the type of activity (analysis, planning, intervention, maintenance); (e) the geo-reference to the hierarchical levels and elements of the semantic structure of the cultural assets. $3 \mathrm{D}$ representation is the main core of this kind of IS, and therefore visualisation and interaction procedures are key elements for its overall usability. 


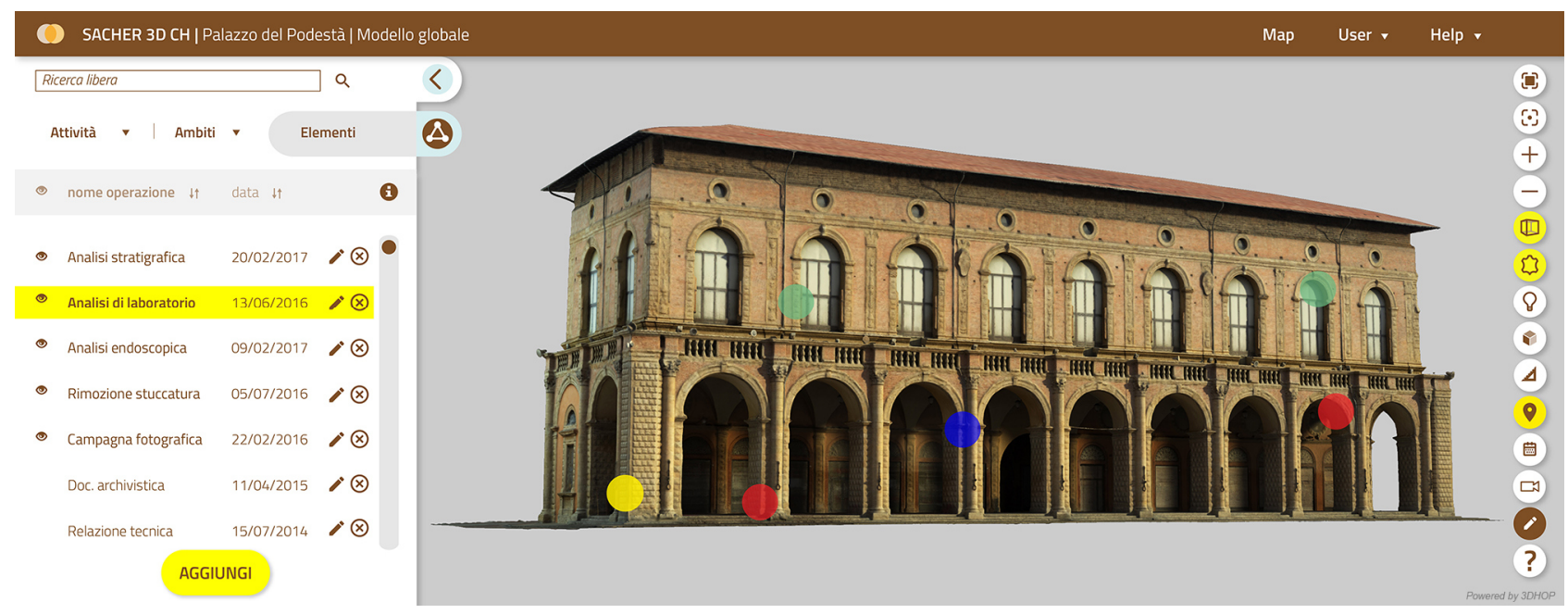

Figure 4. SACHER 3D CH interface and 3D annotation tools for the pilot case study (Palazzo del Podestà, Bologna)

This means: availability of a semantic structure, meant as conceptual and generative structure of a 3D model-based knowledge system; tools for visualising and browsing throughout the 3D models; user interface for adding annotations directly onto a 3D model; three-dimensional exploration of the Information System.

\subsection{Comparison between platforms}

The two mentioned case studies were substantially designed as simplified online tools for end users involved in restoration and administrative activities to manage Cultural Heritage by means of web platform and dedicated services for information storage and advanced search.

Despite sharing a documentation purpose, nevertheless they were developed with different approach, the first being tailored on the single specific monument and featuring advanced 3D annotation tools, e.g. spot, linear and surface selection; the second potentially customisable both on buildings and works of art, with flexible preferences set by operators such as semantic hierarchies, integrated vocabulary of the standard terminology for describing $\mathrm{CH}$, and the possibility to manage more than one cultural asset located on map by creating a subset accessible by different levels of users; while additionally integrated with services able to retrieve existing information and data available in different databases.

Both are web-based, password-protected and accessible in multi-user mode, and are provided with and a user-friendly interface and advanced $3 \mathrm{D}$ visualisation, navigation and annotation tools.

As regards the 3D model, the Neptune's IS was centred on a very accurate, textured and high-resolution 3D model (610 million triangles; geometric surface accuracy equal to $0.2 \mathrm{~mm}$ ), outcome of the joint work by the Geomatics group of University of Bologna and Studio MCM, each element of which has been acquired through a structured light 3D scanner, aligned on a global TLS-based model and sampled by means of Meshlab software by ISTI-CNR. The complex structure of the model depended on a twofold aspect, related on the one hand to the articulated surface due to the conception of the sculptural groups with the same elements repeated four times at each level and oriented towards the cardinal points, and on the other hand to the constituent material of the elements, that is metal (bronze) or stone (marble or others), independently restored by different teams because requiring a very different restoration process. For this reason, the 3D's granularity envisages a global model, made of 7 hierarchical levels which in their turn consist of 72 elements, except for the additional models describing underground tunnels for water supply.

Instead, the SACHER 3D CH service's core is a photogrammetry-based model from more than 5,000 images, representing the whole external surface of the building, oriented and scaled with topographic reference data.

The model is cardinal points-oriented and has been structured on the basis of a hierarchical organisation, starting with elevation levels corresponding to floors (ground floor, first floor, attic, roofing, etc.), then architectural elements (such as the portico) and finally sub-elements (columns, pillars, vaults, etc.), in addition to two more groupings, that are façade and spans, intensely requested by restorers since corresponding to their way of working and labelling when restoring. This scheme can be potentially extended and modified as it refers to a tree, where father and son elements are connected in an acyclic graph and can be replaced without losing attached information that return to the father.

\section{FUTURE WORKS}

Achieved results bode well of further implementation of the developed platforms, since the testing phase for both has been promising.

Following an internal evaluation period, the Neptune's Fountain IS has been released for the end users participating to the restoration project in order to use all developed tools in the subsequent phases of the work site for several months.

After the conclusion of the restoration, the IS is still working and used by the operators of the Municipality of Bologna, especially for information retrieval of the previous state of preservation of the monument or document query related to the restoration works. Since the design of the data model has envisaged in the initial phase the possible employment of the web platform for the management of the post-restoration activities (considered activities during restoration: analysis step, planning phase, restoration intervention, maintenance), the use of the IS can be easily extended for documenting the routine and/or emergency maintenance service of the fountain.

SACHER 3D CH service received a positive feedback to the assessment questionnaire given subsequent to the use by a sample of $\mathrm{CH}$ experts among restorers, professionals, managers, scholars; as strong points, they listed especially usability and 
usefulness of the innovative tools and advanced features designed, and last but not least the user-friendly interface.

Some additional plugins, which are briefly illustrated, remained at the design level; they have been foreseen for a complete service after brainstorming with experts of the field and can be implemented at any time on the main platform.

The first is the timeline navigation mode with highlights in different colours according to processes and activities (Figure 5), that is the working phases summarised in a graphic line showing the sequence of events, possibly filtered on definite actions and/or limited periods. In this way, the tool provides an overview of the development of the restoration work, easily searchable for specific contents and allowing a better management of the works performed, including some automatic warnings for scheduled maintenance works or necessary actions (statements of account of work, payments on account, etc.).

The tool is directly linked to the automatic daily record of the uploaded data, stored in the service under different categories during the data-entry step. User queries on records are exportable in pdf format with different filtering methods, such as type of activity, period, quantitative surface data, analytics per operator, man-hours, etc. These activity reports offer a great help to keep a close watch on the restoration progress similarly for the bill of quantities, offering a clear layout for daily/weekly/monthly summary, and can include any material attached to operations (photos, URL links, information, 3D models previews, etc.). An user could also export the whole project or only a specified period or action (e.g. surface cleaning of marble stone), having all the material organised per $\mathrm{day} / \mathrm{week} / \mathrm{month}$ and in sections related to the different kinds of files uploaded. Moreover the web-based activity reporting tool is strongly needed by companies to easily check man-hours spent in a certain area compared to the allocated amount for the specific activity.

Another implementation concerns the surface mapping on the 3D model for visualising coloured areas for different operations, as already achieved in the Neptune IS. In fact, working directly on the three-dimensional surface can be quite complicated for non-expert users at the beginning, but has undeniable advantages: firstly, in the possibility of visualising the object with accurate geometry and high-quality texture not on-site, and secondly, to display the selected areas highlighted in various colours according to different interventions, so to help users understand with one quick look the extent of the work performed or to be done.

Concerning the 3D content, there are additional toolkits designed to enhance navigation in the virtual space, e.g. transparent limit box mode and non-textured visualisation for disabled elements of the context/global model (at the moment completely hidden) to allow users orient themselves correctly; smart view setting mode for quickly selecting the main views of the object (top, front, etc.); exportable snapshots and reports of the work performed for online validating progress. This last tool is useful both for the administration to actively monitor ongoing progress in the work and for the operators, having available a single system for annotation.

The service is already allowing users to define hierarchical and relational structure of the $3 \mathrm{D}$ data, i.e. tree diagrams for inserting the 3D model with a data structure of nodes attached in parent-child relationships, with levels corresponding to floors if the object is a building and then sub-levels to architectural elements and so on. But, in view of the fact to possibly extend the aim of the tool also to other works of art, we designed different resources to create custom-built graphs to cover all possible needs for users and different objects, e.g. materialdriven graphs or with compass if referenced to cardinal points.
Moreover, 3D upload could include (i) tags for materials, in order to count surfaces for statistics or for calculation with a highest degree of accuracy of products necessary for the estimate of cleaning operations or for coats of protective layers; (ii) the possibility to associate different textures to the model, for instance before and after restoration, to document exactly changes occurred to the surfaces.

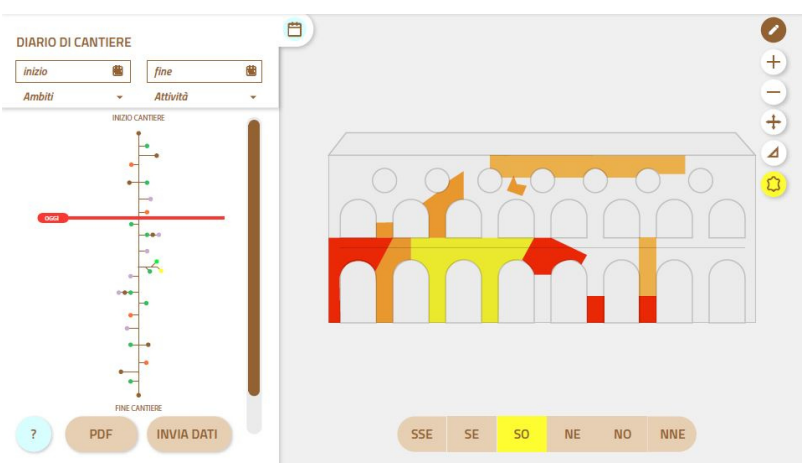

Figure 5. Plugin interface for the timeline of restoration activities designed as tool to easily check the progress of the work and graphic scheme of activities on elevations. Model: F.I.

Apollonio, S. Bertacchi; Design: F. Rizzo, G. Dall'Osso

\section{CONCLUSIONS}

Despite the experiences carried out and the potential offered, ICT-based technological innovation has not yet made substantial advantages in the Cultural Heritage field, both as regards the management and concerning the use of assets, whereas ICT-based technologies could play a major role (Gaiani et al., 2016b). While great effort has been devoted to developing these IS, some problems are still a pending issue on a more general level, among others a large amount of highly heterogeneous data, discontinuity and isolation of systems, manual data-entry, creation of not scalable contents for each level, lack of integration between involved parties, complexity and incompleteness of data, high-cost of $3 \mathrm{D}$ digitisation for predominant manually-based techniques carried out by experts, 3D models often taken out of context, etc. The digitisation extended to the entire process, hoped for many years, or novel and powerful Information Systems based on reality-based 3D models as replicas of the original artefact with complete chromatic, graphic and metric features, are in fact no longer sufficient looking ahead.

Besides further tools not yet implemented in recent web-based IS, that may be subject to future developments with a view to completing all the user tools made available for the service, it is still weak, e.g., the reception of the Internet of Things (IoT) paradigm to create a model of global knowledge linking the electronic to the physical world, easily shareable to any user and with the aim to transform Cultural Items into Smart Cultural Objects (SCO), sources and recipients of advanced information capable of taking an active role in information (Gaiani et al., 2015b). This information framework enabled by IoT with tagged links could provide a means for efficiently collecting, generating and sharing knowledge between various service stakeholders, public (citizens and tourists) and private (managers and institutions), and become a fully integrated system containing sensing, storage, analytics and interpretation data (Gaiani, 2017).

Immediate usability, additional monitoring, portability via contactless devices, small size, energy efficiency, low cost and easy integration into the existing systems, large-scale 
deployment, deployment sustainability, limited visual impact, non-invasive presence are just a few of the benefits that make IoT a viable path for achieving even more innovative results and make a valuable contribution to emphasise the knowledge processes through augmentation of past memories with information interfaces, allowing a complete management of the Heritage artefact from conservation to communication.

\section{ACKNOWLEDGEMENTS}

Authors would like to thank the Municipality of Bologna, the participants to the project for the restoration of the Neptune's Fountain, the SACHER project partners, and all colleagues involved in the two projects which results are presented in the case studies section.

\section{REFERENCES}

Adembri, B., Cipriani, L., Bertacchi, G., 2017. Guidelines for a Digital Reinterpretation of Architectural Restoration Work: Reality-Based Models and Reverse Modelling Techniques applied to the Architectural Decoration of the Teatro Marittimo, Villa Adriana. Int. Arch. Photogramm. Remote Sens. Spatial Inf. Sci., XLII-5/W1, 599-606. doi.org/10.5194/isprs-archivesXLII-5-W1-599-2017.

Apollonio, F.I., 2018. The Production of 3D Digital Archives and the Methodologies for Digitally Supporting Research in Architectural and Urban Cultural Heritage. Münster, S., Friedrichs, K., Niebling, F., Seidel-Grzesińska, A. (eds), Digital Research and Education in Architectural Heritage. UHDL 2017, DECH 2017. CCIS, 817. Springer, Cham, 139-158. doi.org/10.1007/978-3-319-76992-9_9.

Apollonio, F.I., Baldissini, S., Beltramini, G., Borgherini, M.M., Clini, P., Gaiani, M., Palestini, C., Sacchi, L., Trevisan, C., 2015. I geo-modelli per la PalladioLibrary: un archivio condiviso e in divenire | Geo-models for the PalladioLibrary: a shared archive in the making. Disegnare idee immagini, 47/2013. Gangemi Editore, Roma, 46-59.

Apollonio, F.I., Baldissini, S., Clini, P., Gaiani, M., Palestini, C., Trevisan, C., 2013. The Palladiolibrary Geo-Models: an Open 3D Archive to Manage and Visualize InformationCommunication Resources about Palladio. Int. Arch. Photogramm. Remote Sens. Spatial Inf. Sci., XL-5/W2, 49-54. doi.org/10.5194/isprsarchives-XL-5-W2-49-2013.

Apollonio, F.I., Ballabeni, M., Bertacchi, S., Fallavollita, F., Foschi, R., Gaiani, M., 2017a. From Documentation Images to Restauration Support Tools: a Path following the Neptune Fountain in Bologna Design Process. Int. Arch. Photogramm. Remote Sens. Spatial Inf. Sci., XLII-5/W1, 329-336. doi.org/10.5194/isprs-archives-XLII-5-W1-329-2017.

Apollonio, F.I., Ballabeni, M., Bertacchi, S., Fallavollita, F., Foschi, R., Gaiani, M., 2018a. Digital documentation and restoration tools reusing existing imagery: a multipurpose model of the Neptune's Fountain in Bologna. Appl. Geomat., 10(4), 295-316. doi.org/10.1007/s12518-018-0210-x.

Apollonio, F.I., Basilissi, V., Callieri, M., Dellepiane, M., Gaiani, M., Ponchio, F., Rizzo, F., Rubino, A.R., Scopigno, R., Sobra', G., 2018b. A 3D-centered information system for the documentation of a complex restoration intervention. J. Cult. Herit., 29, 89-99. doi.org/10.1016/j.culher.2017.07.010.
Apollonio, F.I., Gaiani, M., Basilissi, W., Rivaroli, L., $2017 \mathrm{~b}$. Photogrammetry Driven Tools to Support the Restoration of Open-Air Bronze Surfaces of Sculptures: an Integrated Solution starting from the Experience of the Neptune Fountain in Bologna. Int. Arch. Photogramm. Remote Sens. Spatial Inf. Sci., XLII-2/W3, 47-54. doi.org/10.5194/isprs-archives-XLII-2-W347-2017.

Apollonio, F.I., Gaiani, M., Benedetti, B., 2012. 3D realitybased artefact models for the management of archaeological sites using 3D GIS: a framework starting from the case study of the Pompeii Archaeological area. Journal of Archaeological Science, 39(5), 1271-1287. doi.org/10.1016/j.jas.2011.12.034.

Apollonio, F.I., Gaiani, M., Sun, Z., 2017c. A Reality Integrated BIM for Architectural Heritage Conservation. Handbook of Research on Emerging Technologies for Architectural and Archaeological Heritage. IGI Global, Hershey, PA, 31-65. doi.org/10.4018/978-1-5225-0675-1.ch002.

Apollonio, F.I., Rizzo, F., Bertacchi, S., Dall'Osso, G., Corbelli, A., Grana, C., 2017d. SACHER: Smart Architecture for Cultural Heritage in Emilia Romagna. Grana, C., Baraldi, L. (eds), Digital Libraries and Archives. IRCDL 2017. CCIS, 733. Springer, Cham, 142-156. doi.org/10.1007/978-3-319-681306_12.

Baldissini, S., Gaiani, M., 2014. Interacting with the Andrea Palladio Works: The History of Palladian Information System Interfaces. Journal on Computing and Cultural Heritage Special Issue on Interacting with the Past, 7(2), 11:1-11:26. doi.org/10.1145/2611374.

Ballabeni, M., Fallavollita, F., Foschi, R., Perugini, G., 2015. Semantic description of three-dimensional models of Bologna porches. SCIRES-IT, 5(1), 31-40. dx.doi.org/10.2423/i22394303v5n1p31.

Baracchini, C., Lanari, P., Scopigno, R., Tecchia, F., Vecchi, A., 2003. SICAR: geographic information system for the documentation of restoration analyses and intervention. Proc. SPIE 5146, Optical Metrology for Arts and Multimedia, 149161. doi.org/10.1117/12.501505.

Beltramini, G., Gaiani, M., 2018. PALLADIOlibrary - A growing virtualization project to understand Andrea Palladio's $\begin{array}{llll}\text { works. } & \text { 73-84. }\end{array}$ doi.org/10.2423//i22394303v7n2p73.

Benedetti, B., Gaiani, M., Remondino, F. (eds), 2010. Modelli digitali $3 D$ in archeologia: il caso di Pompei. Edizioni della Normale, Pisa.

Bertacchi, S., Al Jawarneh, I.M., Apollonio, F.I., Bertacchi, G., Cancilla, M., Foschini, L., Grana, C., Martuscelli, G., Montanari, R., 2018. SACHER Project: A Cloud Platform and Integrated Services for Cultural Heritage and for Restoration. Goodtechs '18 Proceedings of the 4th EAI International Conference on Smart Objects and Technologies for Social Good, 283-288. doi.org/10.1145/3284869.3284871.

Carboni, N., De Luca, L., 2017. Towards a Semantic Documentation of Heritage Objects through Visual and Iconographical Representations. International Information \& $\begin{array}{llll}\text { Library } & \text { Review, } & 49 & \text { (3), }\end{array}$ doi.org/10.1080/10572317.2017.1353374. 
Foni, A.E., Papagiannakis, G., Magnenat-Thalmann, N., 2010. A taxonomy of visualization strategies for cultural heritage applications. Journal on Computing and Cultural Heritage, 3(1), 1-21. doi.org/10.1145/1805961.1805962.

Fontana del Nettuno, 2019. http://nettuno.comune.bologna.it (last accessed 03.10.19).

Gaiani, M., 2012. Creare Sistemi informativi per studiare, conservare, gestire e comunicare sistemi architettonici e archeologici complessi. DISEGNARECON, 5(10), 9-20. doi.org/10.6092/issn.1828-5961/3277.

Gaiani, M., 2015. I portici di Bologna: architettura, modelli 3D e ricerche tecnologiche. Bononia University Press, Bologna.

Gaiani, M., 2017. Management and communication of archaeological artefacts and architectural heritage using digital IS. What today? What next?. Archeologia e Calcolatori, XXVIII.2, 421-435. doi.org/10.19282/AC.28.2.2017.34.

Gaiani, M., Apollonio, F.I., Ballabeni, A., Remondino, F., 2017. Securing Color Fidelity in 3D Architectural Heritage Scenarios. Sensors, 17(11), 2437. doi.org/10.3390/s17112437.

Gaiani, M., Apollonio, F.I., Ballabeni, A., Remondino, F., 2016a. A technique to ensure color fidelity in automatic photogrammetry. Gadia, D. (ed), Colour and colorimetry. Multidisciplinary contributions, XII/b. Gruppo del Colore Associazione Italiana Colore, Milano, 53-66.

Gaiani, M., Apollonio, F.I., Clini, P., Quattrini, R., 2015a. A mono-instrumental approach to high-quality 3D reality-based semantic models application on the PALLADIO library. 2015 Digital Heritage, 29-36. doi.org/10.1109/DigitalHeritage.2015.7419449.

Gaiani, M., Apollonio, F.I., Martini, B., 2015b. A design framework for Smart Cultural Objects. Strategic Design Research Journal, $\quad 8(1), \quad 21-28$. doi.org/10.4013/sdrj.2015.81.04.

Gaiani, M., Apollonio, F.I., Toscano, E., 2016b. A framework to support active management and communication of Cultural Objects. 2016 IEEE 2nd International Forum on Research and Technologies for Society and Industry Leveraging a Better Tomorrow (RTSI), 1-6. doi.org/10.1109/RTSI.2016.7740550.

Gaiani, M., Gamberini, E., Tonelli, G., 2001. VR as work tool for architectural \& archaeological restoration: the ancient Appian way 3D web virtual GIS. Proceedings Seventh International Conference on Virtual Systems and Multimedia, 86-95. doi.org/10.1109/VSMM.2001.969659.

Gaiani, M., Remondino, F., Apollonio, F.I., Ballabeni, A., 2016c. An Advanced Pre-Processing Pipeline to Improve Automated Photogrammetric Reconstructions of Architectural Scenes. Remote Sensing, 8(3), 178. doi.org/10.3390/rs8030178.

Galeazzi, F., Callieri, M., Dellepiane, M., Charno, M., Richards, J., Scopigno, R., 2016. Web-based visualization for 3D data in archaeology: The ADS 3D viewer. Journal of Archaeological Science: Reports, 9, 1-11. doi.org/10.1016/j.jasrep.2016.06.045.
Garozzo, R., Murabito, F., Santagati, C., Pino, C., Spampinato, C., 2017. CULTO: An Ontology-Based Annotation Tool for Data Curation in Cultural Heritage. Int. Arch. Photogramm. Remote Sens. Spatial Inf. Sci., XLII-2/W5, 267-274. doi.org/10.5194/isprs-archives-XLII-2-W5-267-2017.

Italy-UNESCO WHL, 2019. UNESCO World Heritage Centre World Heritage List - Italy. https://whc.unesco.org/en/list/ (last accessed 03.10.19).

Messaoudi, T., Véron, P., Halin, G., De Luca, L., 2018. An ontological model for the reality-based 3D annotation of heritage building conservation state. J. Cult. Herit., 29, 100112. doi.org/10.1016/j.culher.2017.05.017.

MiBACT, 2019. Ministero dei beni e delle attività culturali e del turismo. http://www.beniculturali.it (last accessed 03.10.19).

Pintus, R., Pal, K., Yang, Y., Weyrich, T., Gobbetti, E., Rushmeier, H., 2016. A Survey of Geometric Analysis in Cultural Heritage. Computer Graphics Forum, 35, 4-31. doi.org/10.1111/cgf.12668.

Potenziani, M., Callieri, M., Dellepiane, M., Corsini, M., Ponchio, F., Scopigno, R., 2015. 3DHOP: 3D Heritage Online Presenter. Computers \& Graphics, 52, 129-141. doi.org/10.1016/j.cag.2015.07.001.

SACHER 3D CH, 2019. SACHER 3D Life Cycle Management for Cultural Heritage. http://3d.sacherproject.com/ (last accessed 03.10.19).

Scopigno, R., Dellepiane, M., 2017. Integration and Analysis of Sampled Data: Visualization Approaches and Platforms. Masini, N., Soldovieri, F. (eds), Sensing the Past. Geotechnologies and the Environment, 16. Springer, Cham, 377-393. doi.org/10.1007/978-3-319-50518-3 18.

Shi, W., Kotoula, E., Akoglu, K., Yang, Y., Rushmeier, H., 2016. CHER-Ob: A Tool for Shared Analysis in Cultural Heritage. Catalano, C.E., De Luca, L. (eds), GCH 2016 Eurographics Workshop on Graphics and Cultural Heritage. The Eurographics Association, CH, 1-4. doi.org/10.2312/gch.20161404.

SICaR, 2019. SICaR Sistema Informatico per la Documentazione e la Progettazione dei Cantieri di Restauro. www.sicar.beniculturali.it (last accessed 03.10.19).

Siotto, E., Baracchini, C., Santamaria, U., Scopigno, R., 2016. Sperimentazione del sistema ministeriale SICaR w/b per la gestione e la consultazione informatizzata dei dati sulla policromia. Archeologia e Calcolatori, XXVII, 131-151. doi.org/10.19282/AC.27.2016.07.

Soler, F., Melero, F.J., Luzón, M.V., 2017. A complete 3D information system for cultural heritage documentation. J. Cult. Herit., 23, 49-57. doi.org/10.1016/j.culher.2016.09.008

Wang, Z., Shi, W., Akoglu, K., Kotoula, E., Yang, Y., Rushmeier, H., 2018. CHER-Ob: A Tool for Shared Analysis and Video Dissemination. Journal on Computing and Cultural Heritage, 11(4), 1-22. doi.org/10.1145/3230673. 